\title{
Efficiency Measurement in Network Industries: Application to the Swiss Railway Companies*
}

\author{
MEHDI FARSI \\ University of Lugano \\ Department of Economics, Center for Energy Policy and Economics, and Swiss Federal Institute of \\ Technology \\ ETH Zentrum, WEC, 8092 Zurich, Switzerland \\ E-mail:mfarsi@ethz.ch
}

MASSIMO FILIPPINI

University of Lugano Department of Economics, Center for Energy Policy and Economics, and Swiss Federal Institute of Technology ETH Zentrum, WEC, 8092 Zurich, Switzerland E-mail: mfilippini@ethz.ch

WILLIAM GREENE

New York University Department of Economics, Stern School of Business 44 West 4th St., New York, NY 10012, USA E-mail: wgreene@stern.nyu.edu

\begin{abstract}
The persistence of increasingly high government subsidies in Switzerland's railroads has led the federal and cantonal authorities to discussing the possibility of high-powered incentive contracts such as those based on cost efficiency benchmarking. Railways are however, characterized by a high degree of unobserved heterogeneity that could bias the efficiency estimates. This paper examines the performance of several panel data models to measure cost efficiency in network industries. The unobserved firm-specific effects and the resulting biases are studied through a comparative study of several stochastic frontier models, applied to a panel of 50 railway companies operating over a 13-year period.
\end{abstract}

Key words: cost efficiency, incentive regulation, railroads, scale economies.

JEL Classifications: L92, L50, L25

* The authors wish to thank Michael Crew and two anonymous referees for their helpful suggestions. Aurelio Fetz provided an excellent assistance, which is gratefully acknowledged. Any remaining errors are the responsibility of the authors. 


\section{INTRODUCTION}

The railroad system in Switzerland consists of two sectors. The first sector includes the international and inter-regional transports. This sector is monopolized by the Swiss Federal Railways, which operates more than half of the railway networks in Switzerland. The second sector provides regional and local transport services that account for about a third of Switzerland's railway passengers. Today, this sector consists of 49 Regional Railway Companies (RRC) with an average network length of approximately $40 \mathrm{~km} .{ }^{1}$ In general the main function of an RRC is to link a rural region to the intercity railway network or to an urban transport network.

The RRCs operate with a regional monopoly license given by the Confederation. ${ }^{2}$ This license defines the RRC's responsibilities, which imply an obligation to provide regular services according to a fixed time table and to apply the official tariff scheme. Moreover, the RRC receives subsidies for their deficit in operating costs and the infrastructure investments from the Confederation and the corresponding canton.

In 1996, following an alarming growth in government subsidies for railway transport in Switzerland, the federal government introduced a series of regulatory reforms. ${ }^{3}$ In particular, the subsidization of RRCs that was previously based on full coverage of deficits has been replaced by an ex-ante fixed payment system. The federal and cantonal governments commission the transport companies for services on the basis of an estimated compensation defined in advance to cover the planned costs, which are not otherwise covered. In addition, the new regulations provide the possibility of competitive tendering for assigning the licenses, whereby the most performing railway companies would be incited to offer the transport service satisfying the conditions imposed by the cantonal regulator. However, tendering is an optional measure and has not been used in any cantons to date.

Although the ex-ante fixed payment rule represents an improvement with respect to previous subsidization practices, without a benchmarking analysis it does not contain incentives to minimize costs. Given that these subsidies are determined through a long series of negotiations and bargaining between railway companies and the corresponding cantonal governments, companies might use their local

1 The regional railways are owned by different Swiss governments (Confederation, cantons and municipalities) and by some private investors. However, the share of private ownership is low.

2 Switzerland is a confederation composed of 26 cantons and approximately 3000 municipalities. Each canton has a high degree of autonomy in the organization, planning and regulation of the local public transport.

3 In 1995 the Swiss parliament approved the revision of the Railway Act (1995), which came into effect as of January 1, 1996. Moreover, in 1999, following the changes in the transport policy at the European level (EC Directive 91/440), further measures have been introduced. These measures include reinforcement of the fixed payment system; separation of infrastructure and transport services in terms of organization and accounting; and provision of open network access in freight transport. The latter does not apply to regional railways, which mainly provide short-distance passenger services. 
monopoly power to maintain high subsidies. Therefore, in the last years some cantonal authorities have begun to use simple benchmarking analysis of costs to determine the level of subsidies. The federal and cantonal authorities have been discussing the possibility to adopt high-powered incentive contracts based on yardstick competition model proposed by Schleifer (1985). ${ }^{4}$ In this context cost frontier models could be useful as a benchmarking tool to induce efficiency but also as a complementary control instrument to determine the amount of subsidies granted to the RRCs. A similar approach has been used in the regulation of water supply in Italy, where a yardstick competition model based on cost estimation has been applied (Antonioli and Filippini 2001).

A number of studies such as Cantos and Maudos (2001), Coelli and Perelman (2000) and Gathon and Perelman (1992) have explored the application of frontier models in railways. However, only a few papers have adopted a stochastic frontier approach. ${ }^{5}$ Railway networks are characterized by a high level of output heterogeneity. Networks with different shapes and densities have different organization and coordination problems, thus different costs. Furthermore, environmental characteristics such as topography and climate can influence the operating costs. In many cases, the information is not available for all output and environmental characteristics. Many of these characteristics are therefore omitted from the cost function specifications. Moreover, there exist other omitted variables such as differences across companies in accounting procedures that are generally not taken into account.

Unobserved firm-specific heterogeneity can be taken into account with conventional fixed or random effects in a panel data model. In order to distinguish external heterogeneities from cost efficiency, Greene $(2005,2004)$ proposed an approach that integrates an additional stochastic term representing inefficiency in both fixed and random effects models. ${ }^{6}$ These models assume that the firm-specific heterogeneity does not change over time but sources of inefficiency vary both across firms and over time. In this paper we use a 'true random-effects' model, which is a random-constant frontier model, obtained by combining a conventional randomeffects model with a skewed stochastic term representing inefficiency. The extended model includes separate stochastic terms for latent heterogeneity and inefficiency. Since many of the unobserved factors, especially those related to the network's shape, are likely to be correlated with the output and perhaps other explanatory variables, the random-effect estimators of the cost function coefficients could be

4 For a discussion of this issue see Tromp (2003) and Federal Office of Transport (2003). See also Dalen and Gòmez-Lobo (2003) for an application of yardstick competition in another transport sector namely, bus industry.

5 See Oum et al. (1999) for a survey of this literature.

6 Kumbhakar (1991) proposed a similar approach using a three-stage estimation procedure. See also Heshmati and Kumbhakar (1994) and Kumbhakar and Hjalmarsson (1995) for two applications of this model. 
biased. To overcome this shortcoming, the 'true random-effects' model has been adjusted using Mundlak's (1978) formulation. ${ }^{7}$

The empirical results obtained from true random effects models in a variety of applications suggest that modeling unobserved heterogeneity could significantly decrease the inefficiency estimates. ${ }^{8}$ This could lend certain support to the application of benchmarking methods in the regulation of strongly heterogeneous network industries, in which the conventional inefficiency estimates appear to be overstated. Provided that they can sufficiently control for the unobserved heterogeneity across firms, these methods can be used to estimate an order of magnitude of cost-inefficiency in the sector or individual companies. In addition, in the case of the Swiss regional railway sector, such analyses could be used to evaluate the subsidies for transport services.

The purpose of this paper is to study the potential advantages of these extended models in an application to Switzerland's railway companies. In particular, our eventual interest is in models that can exploit the advantage of a fixed-effects model to have an unbiased estimate of the cost function without compromising the estimates of inefficiency scores. The models are estimated for a sample of 50 railway companies operating in Switzerland from 1985 to 1997. The alternative models are compared regarding the cost function slopes and inefficiency estimates. The conventional FE estimators of the cost function coefficients are assumed to be unbiased, thus used as a benchmark to which other models are compared. For the inefficiency estimates, the correlation between different models and the effect of econometric specification have been analyzed. The results suggest that the inefficiency estimates are substantially lower when the unobserved firm-specific effects are taken into account.

The rest of the paper is organized as follows: Sections 2 and 3, respectively, present the model specification and the methodology. The data are explained in Section 4. Section 5 presents the estimation results and discusses their implications, and Section 5 provides the conclusions.

\section{Model Specification}

A railway company can be considered as an aggregate production unit that operates in a given network and transforms labor, capital and energy inputs into units of transport services such as passenger-kilometers of public transport and ton-kilometers of freight. Given the extremely large number of different transport services, the measure of output requires an aggregation of outputs in one way or another. ${ }^{9}$

7 See Farsi et al. (2005) for a discussion of Mundlak's adjustment in frontier models.

8 See for instance Greene (2004), Farsi et al. (2006) and Alvarez et al. (2004).

9 Theoretically, any relation between any two points in the network could be defined as an output type. Estimating a multi-product cost function with so many outputs is practically impossible thus, an aggregation process is inevitable. 
The commonly used measures of output are the number of passenger-kilometers and freight ton-kilometers (Caves et al. 1985; Cantos et al. 1999) and number of wagon-kilometers (Filippini and Maggi 1993; Todani 2001).

A practical way of attenuating the approximation errors due to aggregation is to include output characteristics such as network length or average haul in the model. Different strategies have been used in the literature. Caves et al. (1985) consider the average lengths of trip for freight and passengers and the number of route miles as output characteristics. Filippini and Maggi (1993) have included the network length in their model specification. Ivaldi and $\mathrm{Mc} \mathrm{Cul-}$ lough (2001) and Todani (2001) considered three types of wagon-miles (high-valued, bulk and others) as three main outputs and accounted for average length of haul and the number of road miles as output characteristic. Other papers like Mizutani (2004) and Savage (1997) include additional output characteristics such as number of lines, load factor and station spacing. The empirical evidence suggests that all these characteristics could have significant effects on costs, therefore should be included in the cost model. However, in practice many of these variables are not available in which case more restricted models are used.

Unfortunately, because of lack of sufficient data on many variables ordinarily used in the literature, in this paper we had a restricted choice of specification. We assumed a double-output production process. The outputs are transported passengers measured by the total number of passenger-kilometers in a given year and the transported freight measured as the aggregate number of ton-kilometers. The length of network is included in the model as output characteristics. Three input factors are considered: labor, capital and energy. A total cost function has been considered. ${ }^{10}$

Based on the above specification the total cost frontier can be represented by the following cost function:

$$
T C=f\left(Y, Q, N, P_{K}, P_{L}, P_{E}, d_{t}\right),
$$

where $T C$ is the total annual costs; $Y$ and $Q$ are the numbers of passenger-kilometers and ton-kilometers, respectively; $P_{K}, P_{L}$ and $P_{E}$ are, respectively, the prices of capital, labor and energy; $N$ is the length of network and $d_{t}$ is a vector including 12 year dummies from 1986 to 1997 (year 1985 is the omitted category). The

10 In a preliminary analysis we also estimated a variable cost function. However, the results indicatea positive derivative of the variable cost function with respect to the capital stock, which violates the non-increasing regularity condition. Following Guyomard and Vermersch (1989) and Filippini (1996) we believe that this problem is due to the empirical difficulty in defining the capital stock variable. Due to lack of data we have used a physical measure of the capital stock, which is highly correlated with output and gives rise to a multi-collinearity problem. For this reason we preferred a total cost function, assuming that the companies can modify their capital expenses on a yearly basis. Insofar as this is equally applicable to all companies, the benchmarking analysis is not sensitive to such an assumption. 
year dummies capture the cost changes associated with technical progress as well as other unobserved year-specific factors. ${ }^{11}$

It is generally assumed that the cost function given in (1) is the result of cost minimization given input prices and output and should therefore satisfy certain properties. ${ }^{12}$ Mainly, this function must be non-decreasing, concave, linearly homogeneous in input prices and non-decreasing in output. To estimate the cost function (1), a Cobb-Douglas (log-linear) functional form is employed. We also evaluated the possibility of applying a translog functional form that can account for variation of scale economies with output. However, we decided to exclude this model because it requires a relatively large number of parameters, which creates certain numerical problems in the simulated likelihood maximization for the random-constant model. Moreover, our preliminary estimations (not reported here) showed that this functional form resulted in counter-intuitive results for the sign of output variables. This is perhaps due to multicollinearity problems caused by strong correlation between the second order terms in translog form.

The concavity assumption is automatically satisfied in Cobb-Douglas form. The linear homogeneity restriction can be imposed by normalizing the costs and prices by the price of one of the input factors. Here we considered the energy as the numeraire good. The other theoretical restrictions are verified after the estimation. The cost function can therefore be written as:

$$
\begin{aligned}
\ln \left(\frac{T C_{i t}}{P_{E_{i t}}}\right)= & \alpha_{0}+\alpha_{Y} \ln Y_{i t}+\alpha_{Q} \ln Q_{i t}+\alpha_{N} \ln N_{i t}+\alpha_{S} \ln S_{i t} \\
& +\alpha_{K} \ln \frac{P_{K_{i t}}}{P_{E_{i t}}}+\alpha_{L} \ln \frac{P_{L_{i t}}}{P_{E_{i t}}}+\sum_{t=1986}^{1997} \alpha_{t} d_{t}+\alpha_{i}+\varepsilon_{i t}
\end{aligned}
$$

with $i=1,2, \ldots, N$ and $t=1,2, \ldots, T_{i}$

Subscripts $i$ and $t$ denote the company and year, respectively, $\alpha_{i}$ is a firm-specific effect and $\varepsilon_{i t}$ is an iid error term. As we will explain in the next section, in the recent models proposed by Greene (2005), the stochastic term $\varepsilon_{i t}$ is composed of two parts: a skewed component representing inefficiency and a symmetric part for the random noise.

The adopted specification given in (2) has two restrictions. First, as discussed earlier some output characteristics are omitted form the model. These omitted variables lower the statistical efficiency of the model by increasing the variance of the error components. Therefore, the inefficiency scores might be overestimated. The unobserved factors could also bias the estimation results should they

11 In the cost function estimations it is common to use a linear trend for technical progress. However, our preliminary regressions indicated that the time-variation of costs is strongly non-linear. In fact there is a gradual increase in the beginning of the sample period followed by a decrease in costs. These variations can be explained by many unobserved factors (such as changes in collective labor contracts or seasonal composition of the demand) that change uniformly across companies.

12 For more details on the functional form of the cost function see Cornes $(1992,106)$. 
be correlated with the explanatory variables. Second, as opposed to a flexible functional form like translog, the adopted Cobb-Douglas form does not allow for any second-order terms. The first implication is that the value of scale economies is assumed to be constant regardless of the output level. Given that most of the Swiss regional railway companies are relatively small this assumption is not very restrictive. However, noting that the effects of second-order terms are suppressed into the error components, they could have a similar effect as that of the omitted variables explained above.

In principle, some of the above shortcomings could be addressed by including the input factor demand (share) equations and solving the resulting system of equations with the appropriate cross-equation restrictions. However, combining these equations with a stochastic frontier model needs an econometric development, which is beyond the scope of this paper. The main problem is the fact that the allocative inefficiencies enter the demand equations, thus create a complex error structure (Greene 1997, 127). As Kumbhakar and Lovell have pointed out, a "satisfactory econometric specification" to such a system of equations "remains to be developed" (Kumbhakar and Lovell 2000, 170).

The discussed shortcomings should be considered in the light of this paper's objective, which is focused on illustrating the application of alternative econometric models and evaluating their differences. In view of this fact and the practical difficulties explained above, we contend that the adopted specification is suitable for the purpose of this paper. However, we would like to stress that the estimated values reported here, of both cost efficiency and scale economies cannot be directly used for practical purposes. Rather, the estimation results can only be considered for illustrative purposes and qualitative comparison of different models.

\section{Econometric Models}

Stochastic frontier models have been subject of a great body of literature resulting in a large number of econometric models to estimate cost functions. Kumbhakar and Lovell (2000) provide an extensive survey of this literature. The main models used in this paper are based on Greene's (2005) extension of the original frontier approach proposed by Aigner et al. (1977). In this framework, $\varepsilon_{i t}$ as given in specification (2), is assumed to be a composite stochastic term with a normalhalf-normal distribution, including both idiosyncratic effects and inefficiencies. The additional firm-specific term, $\alpha_{i}$ in Equation (2), represents the unobserved heterogeneity and is assumed to have a normal distribution. This model is referred to as a "true" random-effects model. ${ }^{13}$ The estimation method is based on simulated maximum likelihood.

13 The name "true" is chosen to show that the model keeps the original frontier framework and the extension is done only by including an additional heterogeneity term. 


\begin{tabular}{|c|c|c|c|c|c|}
\hline & $\begin{array}{l}\text { Model I } \\
\text { FE }\end{array}$ & $\begin{array}{l}\text { Model II } \\
\text { RE }\end{array}$ & $\begin{array}{l}\text { Model III } \\
\text { Pooled }\end{array}$ & $\begin{array}{l}\text { Model IV } \\
\text { True RE }\end{array}$ & $\begin{array}{l}\text { Model } V \\
\text { True RE with } \\
\text { Mundlak } \\
\text { Adjustment }\end{array}$ \\
\hline $\begin{array}{l}\text { Firm-specific } \\
\text { component } \alpha_{i}\end{array}$ & Constant & $\begin{array}{l}\text { Half-normal } \\
\mathrm{N}^{+}\left(0, \sigma_{\alpha}^{2}\right)\end{array}$ & None & $\mathrm{N}\left(0, \sigma_{\alpha}^{2}\right)$ & $\begin{array}{l}\alpha_{i}=\gamma \bar{X}_{i}+\delta_{i} \\
\bar{X}_{i}=\frac{1}{T_{i}} \sum_{t=1}^{T_{i}} X_{i t} \\
\delta_{i} \sim \mathrm{N}\left(0, \sigma_{\delta}^{2}\right)\end{array}$ \\
\hline $\begin{array}{l}\text { Random } \\
\text { error } \varepsilon_{i t}\end{array}$ & $i i d\left(0, \sigma_{\varepsilon}^{2}\right)$ & $i i d\left(0, \sigma_{\varepsilon}^{2}\right)$ & $\begin{array}{l}\varepsilon_{i t}=u_{i t}+v_{i t} \\
u_{i t} \sim \mathrm{N}^{+}\left(0, \sigma_{u}^{2}\right) \\
v_{i t} \sim \mathrm{N}\left(0, \sigma_{v}^{2}\right)\end{array}$ & $\begin{array}{l}\varepsilon_{i t}=u_{i t}+v_{i t} \\
u_{i t} \sim \mathrm{N}^{+}\left(0, \sigma_{u}^{2}\right) \\
v_{i t} \sim \mathrm{N}\left(0, \sigma_{v}^{2}\right)\end{array}$ & $\begin{array}{l}\varepsilon_{i t}=u_{i t}+v_{i t} \\
u_{i t} \sim \mathrm{N}^{+}\left(0, \sigma_{u}^{2}\right) \\
v_{i t} \sim \mathrm{N}\left(0, \sigma_{v}^{2}\right)\end{array}$ \\
\hline Inefficiency & $\hat{\alpha}_{i}-\min \left\{\hat{\alpha}_{i}\right\}$ & $\begin{array}{l}E\left[\alpha_{i} \mid \omega_{i 1}, \omega_{i 2}, \ldots\right] \\
\text { with } \omega_{i t}=\alpha_{i}+\varepsilon_{i t}\end{array}$ & $E\left[u_{i t} \mid u_{i t}+v_{i t}\right]$ & $E\left[u_{i t} \mid \alpha_{i}+\varepsilon_{i t}\right]$ & $E\left[u_{i t} \mid \delta_{i}+\varepsilon_{i t}\right]$ \\
\hline
\end{tabular}

The results are compared with other alternative models such as the fixed-effects model proposed by Schmidt and Sickles (1984) and the random-effects model proposed by Pitt and Lee (1981). Both these models are covered by the general form given in (2) with the difference that in the former model $\alpha_{i}$ is a fixed effect and $\varepsilon_{i t}$ is a zero-mean error term with no distribution restriction, and in the latter (Pitt and Lee) model $\alpha_{i}$ is a random effect with half-normal (or truncated normal) distribution and $\varepsilon_{i t}$ is a normal random error term.

A summary of the five models used in the paper is given in Table 1. The first model is a fixed effects (FE) model. In this model the firm-specific effects are considered as constant parameters that can be correlated with the explanatory variables. The coefficients are estimated through "within-firm" variations and therefore, are not affected by heterogeneity bias. ${ }^{14}$ In the cost frontier literature the inefficiency scores are estimated as the distance from the firm with the minimum estimated fixed effect, that is $\hat{\alpha}_{i}-\min \left\{\hat{\alpha}_{i}\right\}$, as proposed by Schmidt and Sickles (1984).

Model II is a random effects (RE) model proposed by Pitt and Lee (1981), which is estimated using the maximum likelihood method. The firm's inefficiency is estimated using the conditional mean of the inefficiency term proposed by Jondrow et al. (1982), ${ }^{15}$ that is: $E\left[\alpha_{i} \mid \omega_{i 1}, \omega_{i 2}, \ldots\right]=E\left[\alpha_{i} \mid \bar{\omega}_{i}\right]$, where $\omega_{i t}=\alpha_{i}+\varepsilon_{i t}$ and $\bar{\omega}_{i}=$ $\frac{1}{T_{i}} \sum_{t=1}^{T_{i}} \omega_{i t}$. A limitation of this model is the assumption that the firm-specific stochastic term $\alpha_{i}$ is uncorrelated with the explanatory variables. Moreover, in both

14 The term "heterogeneity bias" was used by Chamberlain (1982) for the bias due to correlation between individual effects and explanatory variables in a random-effects model. See also Baltagi (2001) for an extensive discussion of fixed-effects (within) estimators.

15 See also Greene (2002). 
models ( $I$ and $I I$ ), inefficiency indicators may include unobserved environmental factors, thus may overstate the firms' inefficiency. There are however two factors that may exacerbate this problem in the FE model. First, unlike the RE model, the firm-specific effects do not follow a single distribution, thus can have a relatively wide range of variation. Second, these effects can be correlated with the explanatory variables, thus can also capture the heterogeneity factors that are correlated with the regressors. Whereas in the RE model in which the firm-specific effects are by construction uncorrelated with the regressors, these factors are suppressed at least partially through the "between" variations, into the regression coefficients.

In the first two models ( $I$ and $I I)$, the firm's inefficiency is assumed to be constant over time, thus captured by the firm-specific effects, while in other models inefficiency can vary across years. Model $I I I$ is a pooled frontier model in that the sample is considered as a cross-section and its panel aspect is neglected. The random error term is divided into two components: a normal error term $v_{i t}$ capturing the noise and a half-normal random term $u_{i t}$ representing the inefficiency as a onesided non-negative disturbance. This model is based on the original cost frontier model proposed by Aigner et al. (1977). The firm's inefficiency is estimated using the conditional mean of the inefficiency term $E\left[u_{i t} \mid u_{i t}+v_{i t}\right]$, proposed by Jondrow et al. (1982).

Models $I V$ and $V$ are extensions to model $I I I$ that include an additional firmspecific random effect $\left(\alpha_{i}\right)$ to represent the unobserved heterogeneity among firms. Model $I V$ is Greene's (2005) true RE model. In this model it is assumed that the unobserved cost differences across firms that remain constant over time, are driven by network-related unobserved characteristics rather than inefficiency. Given the relatively long period covered in the data (12 years on average), this is a realistic assumption. The inefficiency term is assumed to be an iid random variable with half-normal distribution. This implies that the inefficiency is not persistent and each period brings about new idiosyncratic elements thus new sources of inefficiency. This is a reasonable assumption particularly in industries that are constantly facing new technologies. Therefore there are two justifications for such a specification in network industries: The first one is a practical assumption that persistent cost differences are related to unobserved heterogeneity across networks and the second one is based on the conjecture that the sources of inefficiency in network industries are dominated by new technology shocks and the incomplete adaptation of managers facing them.

Model $V$ is an extension of model $I V$ that uses Mundlak's (1978) specification to account for the potential correlation of unobserved firm-specific heterogeneity with the explanatory variables. Mundlak's adjustment (Hsiao 2003, 44 46) can be written as an auxiliary regression given by:

$$
\alpha_{i}=\gamma \bar{X}_{i}+\delta_{i}, \quad \bar{X}_{i}=\frac{1}{T_{i}} \sum_{t=1}^{T_{i}} X_{i t}, \quad \delta_{i} \sim N\left(0, \sigma_{\delta}^{2}\right),
$$

where $X_{i t}$ is the vector of all explanatory variables and $\gamma$ is the corresponding vector of coefficients. Equation (3) actually divides the firm-specific stochastic term 
into two components: The first part can be explained by exogenous variables, whereas the remaining component $\left(\delta_{i}\right)$ is orthogonal to explanatory variables. The advantage of this model is that it allows for a time-variant inefficiency term while minimizing the heterogeneity bias. The heterogeneity bias can be avoided to the extent that the auxiliary equation can capture the correlations.

In our comparative analysis we consider two aspects of the models' performance. The first dimension is the estimation of the cost function's coefficients. In railway companies the operating costs are affected by network characteristics, which may be correlated with explanatory variables such as network's size and input factor prices. For instance, larger networks are more likely to have more complex shapes. Denser networks are usually located in areas with higher population density, where wages are relatively high. Such relationships imply a positive correlation between the output level and labor price with the network complexity, which is not fully captured by the included factors in the model. The Hausman test is used to confirm that the firm-specific effects are correlated with the explanatory variables. In this case the FE estimators (model $I$ ) are unbiased, thus provide a benchmark to which other models can be compared.

The second aspect of the models' performance concerns the inefficiency estimates. It is important to note that the consistency of slopes (coefficients) does not necessarily imply that inefficiency estimates are unbiased. Interestingly, the empirical results suggest that there is a trade-off in estimations. Namely, models (like the FE model) with a good performance on slopes have strongly biased inefficiency estimates. Roughly speaking, the heterogeneity bias may be suppressed into the slopes as it appears in the RE model, or into the efficiency estimates as observed in the FE model. Farsi et al. (2005) provide a discussion on this issue. The results of that study on a sample of nursing homes suggest that Mundlak's formulation can be helpful to reduce the heterogeneity bias in both slopes and inefficiency estimates at the same time. In this paper we use a similar approach to study if such a conclusion can be applied to a network industry.

It should be noted that the inefficiency estimation requires a certain interpretation of the stochastic terms in the model. In the frontier literature, starting from Aigner et al. (1977), it is commonly accepted that the skewed stochastic term with a certain distribution represents inefficiency. Carree (2002) discusses some of the implications of such distribution assumptions. For instance a half-normal distribution through its zero mode, implies that any company is most likely to be completely efficient. Moreover, implicit in this model is the assumption that inefficiency is uncorrelated with all exogenous variables and also with the idiosyncratic variations reflected in the symmetric error term. ${ }^{16}$ In fact, through this assumption all the inefficiencies that are somehow related to exogenous variables such as factor prices and output are excluded from the firm's productive inefficiency. Later studies

16 Here, cost inefficiency is defined as the excess costs due to the firm's technical problems or to suboptimal allocation of resources. Thus, scale inefficiencies, which are related to suboptimal output, are excluded. 
like Cornwell et al. (1990) and Battese and Coelli (1992) extended the original framework to include exogenous variables in the distribution of the inefficiency term. However, in this paper we maintain the original assumption such that the efficiency measures are restricted to the sources that are completely uncorrelated with all exogenous variables, which by definition are beyond the firm's control. The only exception is the FE model (model $I$ ) that allows any correlation of inefficiency scores. Furthermore, we assume that the inefficiency can vary over time, thus for the inefficiency estimates we focus on models $I I I, I V$ and $V$.

\section{Data}

The data set used in this paper is extracted from the annual reports of the Swiss Federal Office of Statistics on public transport companies. The companies operating in main urban centers are excluded from the sample. Most of these companies operate inner-city tramways and buses, whose functioning is quite different from trains. We also excluded one other company whose extremely low total costs and energy expenses suggest the possibility of a reporting error. The final sample includes 50 railway companies over a 13-year period from 1985 to 1997. The sample is an unbalanced panel with number of periods $\left(T_{i}\right)$ varying from 1 to 13 and with 45 companies with 12 or 13 years, resulting in 605 observations in total. ${ }^{17}$ The available information for any given year includes total costs, labor and energy expenses separately, total number of employees, the quantity of consumed electricity, network length, total number of seats and total number of train-kilometers, passenger-kilometers and ton-kilometers.

Capital costs are calculated as the residual costs after deducting the labor and energy expenses from the total costs. These costs are mainly related to equipment and materials. Total number of seats is used as a proxy for capital stock. ${ }^{18}$ Thus, the capital price is calculated as the residual expenses per seat. The passenger and freight outputs are respectively, measured by the number of passenger-kilometers and ton-kilometers. In Switzerland, each railway company is required to run a certain minimum number of trips per day for any given connection, specified by the cantonal regulators. Therefore, the number of train-kilometers or wagon-kilometers could be also an appropriate measure of passenger output. However, in order to be consistent with the recent literature ${ }^{19}$ and also given that there is a high correlation between train-kilometers and passenger-kilometers (a correlation coefficient of 0.97 in our sample) we adopted the number of passenger-kilometers and ton-kilometers.

17 The average number of periods in the sample is 12 years. For 37 companies, the data are available for 13 years. Eight other companies have 12 years available. The number of years available for the remaining five companies is, respectively, 1, 3, 7, 7 and 10 .

18 See Filippini and Prioni (2003) for a similar approach.

19 Some recent examples are Mancuso and Reverberi (2003), Estache et al. (2002), Cantos et al. (1999) and Banos-Pino et al. (2002). 


\begin{tabular}{|c|c|c|c|c|c|}
\hline & Mean & $\begin{array}{l}\text { Standard } \\
\text { Deviation }\end{array}$ & Median & Min. & Max. \\
\hline Total annual costs $(T C)$ CHF million & 26.73 & 49.88 & 8.83 & 2.12 & 307.43 \\
\hline Passenger output $(Y) \times 10^{6}$ passenger-kms & 30.80 & 55.10 & 10.00 & 0.41 & 311.00 \\
\hline Average cost (CHF per passenger-km) & 1.20 & 0.76 & 1.09 & 0.33 & 5.98 \\
\hline Freight output $(Q) \times 10^{6}$ ton-kilometers & 10.20 & 52.70 & 0.27 & 0.00015 & 477.00 \\
\hline Network length $(N)(\mathrm{km})$ & 39.43 & 56.64 & 22.82 & 3.90 & 377.00 \\
\hline Capital price $\left(P_{K}\right)$ per seat $\left(\mathrm{CHF}^{\prime} 000\right)$ & 4.53 & 2.13 & 4.03 & 1.04 & 14.47 \\
\hline $\begin{array}{l}\text { Average labor price }\left(P_{L}\right) \text { per employee per } \\
\text { year (CHF '000) }\end{array}$ & 86.05 & 6.48 & 86.09 & 60.93 & 104.93 \\
\hline Energy (electricity) price $\left(P_{E}\right) \mathrm{CHF} / \mathrm{kWh}$ & 0.157 & 0.023 & 0.158 & 0.076 & 0.265 \\
\hline
\end{tabular}

All the costs and prices are adjusted for inflation using the Switzerland's global price index and are measured in 1997 Swiss Francs.

Table 2 provides a descriptive summary of the main variables used in the analysis. As it can be seen in this table, the total costs show a high variation in the sample. The average cost of a passenger-kilometer varies from 0.3 to about 6 Swiss Francs. There is also a considerable variation in input prices and both outputs in the sample. Given the importance of within variations in most panel data models (especially the fixed-effect model), it is helpful to distinguish these variations from the variations across companies. Table 3 gives a summary of "within" and "between" variations for the main variables used in the regressions. As it can be seen in this table, the dependent variable and most explanatory variables show a fairly considerable amount of within variation, supporting the use of a fixed-effect model. As expected, the within variation of network length is relatively low (limited to $7 \%$ ).

\section{Estimation Results}

The estimation results for the five models are given in Table 4. These results show that the output and input price coefficients are positive and highly significant across all models. The estimated coefficients show a considerable variation across different models. The estimates from the pooled model (III) are particularly different from those of other models. The year dummies are mostly significant and suggest that the cost variation over time is not linear. Again, the pooled model is an exception in which none of these dummies show any statistically significant effect. Noting that model III completely ignores the panel structure of the data, its estimates are likely to be strongly biased by omitted firm-specific variables. On the 
Table 3. Within and Between Variations (50 companies and 12 years on average)

\begin{tabular}{|c|c|c|c|c|c|}
\hline & \multirow[b]{2}{*}{ Mean } & \multicolumn{3}{|c|}{ Standard Deviation } & \multirow[b]{2}{*}{ Fraction of within variation } \\
\hline & & Overall & Between & Within & \\
\hline $\ln \left(\frac{T C}{P_{E}}\right)$ & 11.31 & 1.10 & 1.12 & 0.15 & 0.14 \\
\hline $\ln (Y)^{2}$ & 16.32 & 1.34 & 1.34 & 0.12 & 0.09 \\
\hline $\ln (\mathrm{Q})$ & 12.49 & 2.72 & 2.78 & 0.61 & 0.22 \\
\hline $\ln (\mathrm{N})$ & 3.20 & 0.91 & 0.93 & 0.06 & 0.07 \\
\hline $\ln \left(\frac{P_{K}}{P_{E}}\right)$ & 10.18 & 0.44 & 0.39 & 0.19 & 0.43 \\
\hline $\ln \left(\frac{P_{L}}{P_{E}}\right)$ & 13.22 & 0.16 & 0.13 & 0.10 & 0.62 \\
\hline \multicolumn{6}{|c|}{$\begin{array}{l}\text { For each variable }(X) \text { the between standard deviation is based on companies' average values that is: } \bar{X}_{i}= \\
\frac{1}{T_{i}} \sum_{t=1}^{T_{i}} X_{i t} \text {; and the within standard deviation is based on deviations from companies' averages }\left(X_{i t}-\bar{X}_{i}\right) . \text { The } \\
\text { overall and within statistics are calculated over } 605 \text { company-years and the between statistics are calculated } \\
\text { over } 50 \text { companies. The fraction of within variation is calculated as the ratio of within to overall standard devi- } \\
\text { ation. }\end{array}$} \\
\hline
\end{tabular}

other hand the fixed-effects estimators (model $I$ ) are derived from the within-firm variations and thus unbiased.

The year dummy coefficients (excluding model III) show that the total costs of railway companies rose almost linearly from 1985 to 1992 with an average annual growth rate of about $1.6 \%$, but declined after 1992 with an average rate of about $1.5 \%$ per year. Since total costs and all the continuous explanatory variables are in logarithms, the estimated coefficients can be interpreted as average cost elasticities. For instance, the output coefficients suggest that on average a one percent increase in passenger-kilometers will increase the costs by $0.11-0.49 \%$ depending on the adopted specification. The marginal effect of ton-kilometers is about 10 times lower, suggesting substantially lower variable costs for freight transportation. The coefficient of network length indicates that the marginal cost of a one percent extension in the network keeping the output constant, is approximately equivalent to $0.4 \%$ increase in costs. These results are consistent with the previous empirical results regarding Switzerland's railroad industry (Filippini and Maggi 1993) in that they suggest increasing returns to scale.

Table 4 also indicates that if the pooled model is set aside, the input price coefficients do not vary significantly across different models. The coefficient of labor price, varying between 0.55 and 0.57 (bar model III), is actually comparable to the average share of labor expenses, which is about $52 \%$ in the sample. The capital price coefficient varies between 0.31 and 0.32 (model III excluded), which is considerably below the average share of capital costs in the sample (44\%). This result may suggest that the companies are not so responsive as a constantly cost minimizing behavior should be, to the changes in capital prices. This can be explained by 


\begin{tabular}{|c|c|c|c|c|c|}
\hline & $\begin{array}{l}\text { Model I } \\
\text { FE }\end{array}$ & $\begin{array}{l}\text { Model II } \\
\text { RE }\end{array}$ & $\begin{array}{l}\text { Model III } \\
\text { Pooled }\end{array}$ & $\begin{array}{l}\text { Model IV } \\
\text { True RE }\end{array}$ & $\begin{array}{l}\text { Model } V \\
\text { True RE + Mundlak }\end{array}$ \\
\hline$\alpha_{Y}$ & $0.114^{*}(0.032)$ & $0.200^{*}(0.030)$ & $0.492^{*}(0.015)$ & $0.133^{\star}(0.023)$ & $0.106^{\star}(0.034)$ \\
\hline$\alpha_{Q}$ & $0.014^{\star}(0.006)$ & $0.021^{*}(0.003)$ & $0.030^{*}(0.006)$ & $0.038^{*}(0.004)$ & $0.017^{\star}(0.003)$ \\
\hline$\alpha_{N}$ & $0.448^{*}(0.051)$ & $0.485^{*}(0.039)$ & $0.393^{*}(0.026)$ & $0.432^{*}(0.015)$ & $0.488^{*}(0.035)$ \\
\hline$\alpha_{K}$ & $0.318^{*}(0.017)$ & $0.310^{*}(0.010)$ & $0.171^{*}(0.032)$ & $0.312^{*}(0.008)$ & $0.315^{\star}(0.009)$ \\
\hline$\alpha_{L}$ & $0.546^{*}(0.037)$ & $0.548^{*}(0.029)$ & $0.592^{*}(0.074)$ & $0.568^{*}(0.036)$ & $0.562^{*}(0.034)$ \\
\hline$\gamma_{Y}$ & - & - & - & - & $0.159^{*}(0.050)$ \\
\hline$\gamma_{Q}$ & - & - & - & - & $0.090^{*}(0.013)$ \\
\hline$\gamma_{N}$ & - & - & - & - & $-0.150^{\star}(0.056)$ \\
\hline$\gamma k$ & - & - & - & - & $-0.189^{*}(0.067)$ \\
\hline$\gamma_{L}$ & - & - & - & - & $-0.193(0.180)$ \\
\hline$\alpha_{1986}$ & $0.010(0.015)$ & $0.009(0.041)$ & $0.009(0.056)$ & $0.022(0.027)$ & $0.017(0.035)$ \\
\hline$\alpha_{1987}$ & $0.020(0.015)$ & $0.012(0.031)$ & $0.003(0.056)$ & $0.032(0.025)$ & $0.029(0.031)$ \\
\hline$\alpha_{1988}$ & $0.039^{*}(0.015)$ & 0.028 & $0.010(0.057)$ & $0.051(0.037)$ & $0.049(0.050)$ \\
\hline$\alpha_{1989}$ & $0.065^{\star}(0.016)$ & $0.052(0.046)$ & $0.036(0.057)$ & $0.076^{*}(0.033)$ & $0.074(0.050)$ \\
\hline$\alpha_{1990}$ & $0.084^{\star}(0.016)$ & $0.068(0.036)$ & $0.024(0.058)$ & $0.097^{*}(0.034)$ & $0.94^{*}(0.044)$ \\
\hline$\alpha_{1991}$ & $0.098^{*}(0.017)$ & $0.078^{*}(0.029)$ & $0.030(0.058)$ & $0.114^{\star}(0.028)$ & $0.111^{*}(0.035)$ \\
\hline$\alpha_{1992}$ & $0.111^{*}(0.017)$ & $0.094^{*}(0.034)$ & $0.046(0.058)$ & $0.130^{*}(0.026)$ & $0.122^{\star}(0.034)$ \\
\hline$\alpha_{1993}$ & $0.100^{*}(0.017)$ & $0.081^{*}(0.034)$ & $0.015(0.057)$ & $0.119^{*}(0.026)$ & $0.112^{*}(0.034)$ \\
\hline$\alpha_{1994}$ & $0.082^{*}(0.017)$ & $0.063(0.040)$ & $-0.001(0.056)$ & $0.103^{*}(0.037)$ & $0.093^{*}(0.039)$ \\
\hline$\alpha_{1995}$ & $0.059^{*}(0.016)$ & $0.048(0.032)$ & $0.019(0.057)$ & $0.081^{*}(0.023)$ & $0.064(0.034)$ \\
\hline$\alpha_{1996}$ & $0.037^{*}(0.017)$ & $0.028(0.024)$ & $0.027(0.057)$ & $0.066^{*}(0.022)$ & $0.043(0.025)$ \\
\hline$\alpha_{1997}$ & $0.038^{*}(0.018)$ & 0.030 & $0.019(0.060)$ & $0.063(0.039)$ & $0.042(0.032)$ \\
\hline$\alpha_{0}$ & - & $-4.90^{\star}(0.57)$ & $-8.31^{*}(0.98)$ & $-3.89^{\star}(0.51)$ & $-1.89(2.66)$ \\
\hline$\sigma_{\alpha}$ & - & - & - & $0.783^{\star}(0.027)$ & $0.751^{*}(0.058)$ \\
\hline$\sigma=\sqrt{\sigma_{u}^{2}}+\sigma_{v}^{2}$ & - & $0.807^{\star}(0.14)$ & $0.464^{*}(0.001)$ & $0.109^{*}(0.005)$ & $0.095^{\star}(0.005)$ \\
\hline$\lambda=\sigma_{u} / \sigma_{v}$ & - & $11.37^{\star}(3.81)$ & $2.88^{*}(0.30)$ & $2.58^{*}(0.56)$ & $1.59^{*}(0.031)$ \\
\hline
\end{tabular}

the fact that in the short run railway companies cannot vary much of their capital stock such as equipment and machinery.

Comparing the results from different models in Table 4 shows that all models except model III, have reasonably comparable coefficients. In model III (pooled model) variations over time and within firms are treated exactly similar to those between different firms. Moreover, the unobserved firm-specific effects are completely neglected, which may bias the estimations. A Lagrange Multiplier test on an OLS model strongly rejects the hypothesis that the residuals of a given company are uncorrelated (test statistic of 2990 for a chi-square with 1 degree of freedom), suggesting that the pooled model is mis-specified. Moreover, the Hausman test rejects the hypothesis that the firm-specific effects are uncorrelated with the explanatory variables (test statistic of 61.5 for a chi-square with 17 
degrees of freedom). This result suggests that models that do not account for these correlations can give biased results. Given the relatively high number of periods (on average 12 years) and the reasonable within-company variations (see Table 3 ) in the sample, the fixed effects model's results can be considered as unbiased estimates of the cost function parameters. Therefore, the coefficients estimated from model $I$ are used as a benchmark for assessing the potential heterogeneity bias in other models.

Compared to model $I$, the parameter estimates in the pooled model (III) have the highest differences. The estimated coefficients in the remaining models are fairly close to those of the FE model, suggesting that heterogeneity biases in the coefficients are not substantial. This statement does not apply to the inefficiency estimates, which as we will see later, show considerable biases. As seen in Table 4, there is no clear distinction between models $I I$ and $I V$ concerning the heterogeneity biases. While in certain coefficients model $I V$ is closer to the unbiased estimates (model $I$ ), in some others model $I I$ shows a 'better' performance.

The random effects specification in both models $I I$ and $I V$ has however a shortcoming in that the firm-specific heterogeneity terms $\left(u_{i}\right.$ in model $I I$ and $\alpha_{i}$ in model $I V$ ) are assumed to be uncorrelated with the explanatory variables. If we put any trust in the Hausman specification test, this assumption is not realistic. Moreover, as discussed earlier, it is plausible that some of the unobserved network characteristics be correlated with the network length. Such correlations are taken into account in model $V$ through the auxiliary coefficients' $\gamma_{x}$ ). The results in Table 4 indicate that model $V$ shows the smallest differences with the unbiased estimators of model $I$. This suggests that applying Mundlak's (1978) adjustment to the TRE model (model $I V$ ) can decrease the heterogeneity biases. As shown in the table, the auxiliary coefficients $\left(\gamma_{x}\right)$ are all significant. These coefficients can be interpreted as the correlation effect between the unobserved firm characteristics and the corresponding explanatory variable. For instance, the positive signs of $\gamma_{Y}$ and $\gamma_{Q}$ suggest that keeping all observed factors fixed, networks with higher outputs are more likely to belong to the 'high-cost' or 'difficult' networks; and the negative signs of $\gamma_{N}, \gamma_{K}$ and $\gamma_{L}$ suggest that larger networks and companies that have higher input prices are more likely to be in the 'low-cost' category.

Table 5 provides a descriptive summary of the inefficiency estimates from different models (see Table 1, last row). These estimates represent the relative excess cost of a given firm compare to a minimum level that would have been achieved if the firm had operated as efficiently as the 'best practice' observed in the sample. In comparing different models it should be noted that in the first two models ( $I$ and II), the inefficiency is assumed to be constant over time. Moreover, in these models all the unobserved firm-specific differences are interpreted as inefficiency. As expected, both models $I$ and $I I$, especially the FE model, predict rather unrealistic inefficiency scores averaging about 0.7 to 0.8 and up to a maximum of 2 to 2.5. According to these models, a typical company can save about a third of its costs by a more efficient allocation of resources. These high values indicate that the heterogeneity across companies is an important driver of cost differences and that neglecting it may create a substantial upward bias in inefficiency scores. 


\begin{tabular}{||llllll||}
\hline \hline \multicolumn{1}{||l}{ Table 5. Inefficiency Measures } & & & \\
\hline & $\begin{array}{l}\text { Model I } \\
\text { FE }\end{array}$ & $\begin{array}{l}\text { Model } I I \\
\text { RE }\end{array}$ & $\begin{array}{l}\text { Model III } \\
\text { Pooled }\end{array}$ & $\begin{array}{l}\text { Model } I V \\
\text { True RE }\end{array}$ & $\begin{array}{l}\text { Model } V \\
\text { True RE with Mundlak }\end{array}$ \\
\hline Mean & 0.813 & 0.696 & 0.343 & 0.078 & 0.063 \\
Median & 0.676 & 0.662 & 0.289 & 0.061 & 0.053 \\
Maximum & 2.507 & 1.992 & 0.848 & 0.386 & 0.311 \\
95 percentile & 1.723 & 1.470 & 0.848 & 0.187 & 0.134 \\
Minimum & 0.000 & 0.160 & 0.060 & 0.011 & 0.012 \\
$\mathrm{~N}$ & 605 & 605 & 605 & 605 & 605 \\
\hline
\end{tabular}

In model $I I I$ the inefficiency estimates are in a more realistic range, with an average of 0.34 and a maximum value of 0.85 . These values though still too high to be convincing, are substantially lower than those predicted by models $I$ and $I I$; and this despite the fact that the pooled model (III) does not account for unobserved heterogeneity. This attenuation of inefficiency estimates can be explained by the structure of the inefficiency term in model III. Given that the inefficiency term $\left(u_{i t}\right)$ is assumed to be independently and identically distributed over time and across companies, it cannot fully capture the firm-specific differences that are timeinvariant, thus such differences are partly suppressed into and bias the model's coefficients.

Both models $I V$ and $V$, which have separate stochastic terms for inefficiency and firm-specific heterogeneity, have quite reasonable inefficiency estimates about $6-8 \%$ on average and $31-38 \%$ on maximum. The substantial decrease in these values compared to other models, suggests that these models can separate to a considerable extent, the heterogeneity from the inefficiency. To understand the reasons behind these results, it is helpful to note that the sole difference between models $I I I$ and $I V$ is that model $I V$ includes an additional firm-specific random term $\left(\alpha_{i}\right)$. This term represents the variations across firms, which are about seven times larger than the variation within firms (compare $\sigma_{\alpha}$ to $\sigma$ in the lower panel of Table 4).

Given that the unobserved heterogeneity is potentially correlated with the explanatory variables and that these correlations are not taken into account in model $I V$ the resulting inefficiency scores may capture some of these differences. This issue can be explored by comparing models $I V$ and $V$. In model $V$ the timeinvariant cost differences across companies are separated from inefficiency estimates (as in model $I V$ ). In addition, the possible correlations with explanatory variables are mitigated through auxiliary coefficients. The results in Table 5 show that when such correlations are controlled for (model $V$ ), the inefficiency estimates slightly decline (by about .015 on average and by 0.075 on maximum). According to this model the average (median) company is only 6.3 (5.3) percent inefficient, and the maximum inefficiency in 95 percent of the sample is limited to 13.4 percent. These results suggest that model $V$ not only provides unbiased, or close to 


\begin{tabular}{|c|c|c|c|c|c|}
\hline & $\begin{array}{l}\text { Model I } \\
\text { FE }\end{array}$ & $\begin{array}{l}\text { Model // } \\
\text { RE }\end{array}$ & $\begin{array}{l}\text { Model III } \\
\text { Pooled }\end{array}$ & $\begin{array}{l}\text { Model IV } \\
\text { True RE }\end{array}$ & $\begin{array}{l}\text { Model } V \\
\text { True RE with Mundlak }\end{array}$ \\
\hline Model I & 1 & & & & \\
\hline Model /I & $0.932^{*}$ & 1 & & & \\
\hline Model III & $0.497^{\star}$ & $0.614^{\star}$ & 1 & & \\
\hline Model IV & -0.247 & -0.256 & $-0.158\left[.092^{\star}\right]$ & 1 & \\
\hline Model $V$ & $-0.334^{\star}$ & $-0.320^{\star}$ & $-0.197\left[.105^{\star}\right]$ & $0.948^{*}\left[0.971^{\star}\right]$ & 1 \\
\hline \multicolumn{6}{|c|}{$\begin{array}{l}\text { The correlation coefficients have been estimated over the firms ( } 50 \text { observations) that is, average values over } \\
\text { the sample period are used in models with time-variant inefficiency (III, IV and } V \text { ). } \\
\text { Correlation coefficients based on } 605 \text { observations are given in brackets. } \\
\text { * significant at } 5 \% \text {. }\end{array}$} \\
\hline
\end{tabular}

unbiased, estimates of the cost function's coefficients, it can also better separate the heterogeneity from inefficiency.

The pair-wise correlation coefficients between the inefficiency estimates from different models are listed in Table 6. In order for the correlation coefficients to be comparable, they are calculated at the firm level using 50 observations (one observation for each firm). Namely, in models with time-variant efficiency, the inefficiency score is calculated as the firm's average inefficiency score over the sample period. For models with time-variant inefficiency the correlation coefficients are also given over the 605 observations.

As shown in Table 6, models $I$ and $I I$, and models $I V$ and $V$ show a relatively high correlation. ${ }^{20}$ However, except a few cases the correlation coefficients are quite low, suggesting substantial differences across models. ${ }^{21}$ Especially, models $I V$ and $V$ show a negative correlation with all other models. Given that the correlation coefficients are calculated on company-average inefficiency scores, the weak (and negative) correlations may suggest that the inefficiency estimates vary considerably from one year to another, in which case the correlation between models with constant and time-variant inefficiency should be weak. However, this can only partly explain the observed correlations. In fact the positive and fairly strong correlation between the pooled model III (with time-variant efficiency) and both models $I$ and $I I$ (with time-invariant efficiency) indicates that averaging cannot explain the negative correlations.

The negative correlation coefficients (Table 6) point to a striking distinction between the models $I V$ and $V$ and all other models, which do not distinguish unobserved heterogeneity from inefficiency. The negative correlations manifest especially in model $V$ in which the correlations with observed factors are

20 These results are consistent with Farsi et al. (2005) who used a similar method for a sample of nursing homes.

21 The rank correlations show similar patterns. These results are omitted to avoid repetition. 
taken into account. These values suggest that some of the unobserved network characteristics may actually be negatively correlated with company's average inefficiency. One interpretation is that the relatively complex thus costly networks are more likely to be operated by an efficient management. This is a plausible explanation because the companies with complex networks are more likely to have a general awareness and perhaps the required expertise for technical problems. Such expertise can directly or indirectly contribute to the firm's efficiency. The results in Table 6 highlight the importance of unobserved heterogeneity, as failure to account for such factors can result in a completely misleading and even reverse picture of inefficiencies.

The estimation of a cost function enables us to derive important characteristics of the supply technology such as economies of density and scale. In line with Caves et al. (1985), the economies of density are defined as the inverse of the elasticity of costs with respect to outputs that is, the relative increase in total cost resulting from an increase in outputs, holding all input prices and the network size constant:

$$
\mathrm{ED}=\frac{1}{\frac{\partial \ln T C}{\partial \ln Y}+\frac{\partial \ln T C}{\partial \ln Q}} .
$$

Economies of density exist if the above expression (ED) has a value greater than one. For values of ED below one, we identify diseconomies of density. In the case of $\mathrm{ED}=1$, the company's output minimizes its costs given the network's size.

Slightly different is the definition of economies of scale (ES). ${ }^{22}$ Here, the increase in total costs is brought about by an increase in company's scale that is in both outputs and the network size, holding the factor prices constant. The commonly used definition is the one proposed by Caves et al. (1984), which assumes that any increase in size raises the network size and the outputs with the same proportion. Based on this assumption, ES is defined as:

$$
\mathrm{ES}=\frac{1}{\frac{\partial \ln T C}{\partial \ln Y}+\frac{\partial \ln T C}{\partial \ln Q}+\frac{\partial \ln T C}{\partial \ln N}} .
$$

Similarly, economies of scale exist if ES is higher than 1. Table 7 shows the estimates of scale and density economies as given in Equations (4) and (5), obtained from different models.

As can be seen in Table 7, both economies of density and scale are greater than one across all models, suggesting the presence of unexploited economies in most

22 It should be noted that the adopted definitions of scale and density economies do not necessarily correspond to those based on the production function. In fact, only in homothetic production functions, where the optimal input bundles vary proportionately, the two definitions are equivalent. In this paper, we do not impose homotheticity. However, as we are interested in the cost effects of output, we define the scale and density economies as the inverse of the corresponding cost elasticities. See Chambers (1988) for more details. 


\begin{tabular}{||llllll||}
\hline \hline \multicolumn{1}{||l||}{ Table 7. Economies of Scale and Density } & & & \\
\hline & Model I & Model $I I$ & Model III & Model IV & Model $V$ \\
& FE & RE & Pooled & True RE & True RE + Mundlak \\
\hline ED & 7.79 & 4.51 & 1.91 & 5.82 & 8.18 \\
ES & 1.74 & 1.42 & 1.09 & 1.65 & 1.64 \\
\hline
\end{tabular}

companies in the sample. As expected, the economies obtained from an increase in output density in a given network (density economies) are relatively higher than those gained by extending a company's network (scale economies). The results listed in Table 7 show a variation of the values of ED and ES between different models. This variation can be partially explained by the models' differences with respect to the unobserved network effects. If these effects are correlated with explanatory variables (such as output and network length) the values obtained from the fixed effect model (Model $I$ ) and the Mundlak version of the True RE (Model $V$ ) are unbiased and those of the other three models are biased. Particularly, the values estimated by the pooled model (Model III) are likely to be biased downward. These results suggest that ignoring the unobserved firm-specific effects can bias the estimated coefficients. In fact such biases are driven by possible correlation of unobserved effects with output and network length.

\section{Conclusion}

The most relevant measure included in the railway reform of 1996 is the change from the practice of ex-post deficit coverage to an ex-ante fixed payment system for transport services. In this context cost frontier models could be useful in determining the amount of subsidies granted to the regional railway companies. Moreover, such models could be used for benchmarking analyses aimed at inducing productive efficiency among railway companies. Such applications are however hampered in practice partly because of the strong unobserved heterogeneity in railway networks, which might be confounded with the company's inefficiency. This paper casts some light on the performance of different cost frontier models in presence of unobserved heterogeneity.

Alternative cost frontier models applied to a panel of Swiss railway companies indicate that the estimations particularly the inefficiency estimates, are sensitive to the adopted specification. The data show a considerable unobserved firm-specific heterogeneity that is likely to be correlated with explanatory variables. In such cases unbiased coefficients can be obtained from the fixed effects model. This model's estimates of inefficiency are however unrealistic. In fact, comparing the results across different models suggest that the inefficiency estimates largely depend upon how the unobserved heterogeneity across firms is specified. Panel data models such as Pitt and Lee (1981) and Schmidt and Sickles (1984) that do 
not distinguish between unobserved firm-specific heterogeneity and inefficiency can overestimate the overall inefficiencies or even give misleading patterns of inefficiency. The cost frontier random effects model labeled as 'true' random-effects model (Greene, 2005) provides reasonable estimates of inefficiency suggesting that the inefficiency estimates in other models could be confounded with unobserved heterogeneity. However, the problem of this model is that because of potential correlation between heterogeneity and explanatory variables, the cost function coefficients may be biased (heterogeneity bias), especially as the Hausman specification test confirms the presence of such correlations.

An auxiliary equation in line with Mundlak (1978) can be helpful in this regard. This adjustment has been applied to the 'true' random effects. The resulting specification shows a very low level of heterogeneity bias, while slightly reducing the inefficiency estimates. The high correlation between the inefficiency scores across the two models suggests that in so far as the heterogeneity is accounted for, the correlation between heterogeneity and explanatory variables does not considerably affect the inefficiency estimates.

From a policy point of view, this study suggests that the Mundlak version of the "true" random effects model is a promising technique that could be used in regulation of railway networks. While emphasizing that a mechanical use of any of these models could be misleading, we contend that cost frontier models can be used as a complementary control instrument in benchmarking and evaluation of subsidy requests in the Swiss Regional Railways. For instance, as shown by Farsi and Filippini (2004) for the case of electricity networks, the regulator could use these models to predict a confidence interval for the costs of each one of the firms. Acceptable intervals for revenue and price caps can be calculated accordingly. Using such predictions along with other monitoring instruments, the regulator can hold the companies within a reasonably well-predicted range of cost-efficiency.

\section{References}

Aigner, D., C. A. K. Lovell and P. Schmidt. 1977. "Formulation and Estimation of Stochastic Frontier Production Function Models." Journal of Econometrics 6: 21-37.

Alvarez, A., C. Arias and W. Greene. 2004. "Accounting for unobservables in production models: management and inefficiency." Working paper No. E2004/72, Centro de Estudios Andaluces, Spain.

Antonioli, B. and M. Filippini. 2001. "The Use of a Variable Cost Function in the Regulation of the Italian Water Industry." Utilities Policy 10(3-4): 181-187.

Banos-Pino, J., V. Fernandez-Blanco and A. Rodriguez-Alvarez. 2002. "The Allocative Efficiency Measure by Means of a Distance Function: The Case of Spanish Public Railways." European Journal of Operational Research 137: 191-205.

Baltagi, B. H. 2001. Econometric Analysis of Panel Data, 2nd edition, Newyork: John Wiley.

Battese, G. E. and T. J. Coelli. 1992. "Frontier Production Functions, Technical Efficiency and Panel Data: with Application to Paddy Farmers in India." Journal of Productivity Analysis 3(1): 153-169.

Cantos, P., J. M. Pastor and L. Serrano. 1999. "Productivity, Efficiency and Technical Change in the European Railways: A Non-parametric Approach." Transportation 26: 337-357.

Cantos, P. and J. Maudos. 2001. "Regulation and Efficiency: The Case of European Railways." Transportation Research Part A 35: 459-472. 
Carree, M. A. 2002. "Technological Inefficiency and the Skewness of the Error Component in Stochastic Frontier Analysis." Economics Lettere 77: 101-107.

Caves, D. W., L. R. Christensen and M. W. Tretheway. 1984. "Economies of Density versus Economies of Scale: Why Trunk and Local Service Airline Costs Differ". Rand Journal of Economics 15(4): 471-489.

Caves, D. W., L. R. Christensen, M. W. Tretheway and R. J. Windle. 1985. "Network Effects and the Measurement of Returns to Scale and Density for U.S. Railroads." In Analytical Studies in Transpot Economics, edited by A. F. Daugherty, Cambridge: University Press, pp. 97-120.

Chamberlain, G. 1982. "Multivariate Regression Models for Panel Data." Journal of Econometrics 18: $5-46$.

Chambers, R. G. 1988. Applied Production Analysis. Cambridge: Cambridge University Press.

Coelli, T. and S. Perelman. 2000. "Technical Efficiency of European Railways: A Distance Function Appraoch." Applied Economics 32: 1967-1976.

Cornes, R. 1992. Duality and Modern Economics. Cambridge: Cambridge University Press.

Cornwell, C., P. Schmidt and R. C. Sickles. 1990. "Production Frontiers with Cross-sectional and Timeseries Variation in Efficiency Levels." Journal of Econometrics 46: 185-200.

Dalen, D. M. and A. Gòmez-Lobo. 2003. "Yardsticks on the Road: Regulatory Contracts and Cost Efficiency in the Norwegian Bus Industry." Transportation 30: 371-386.

Estache, A., M. Gonzalez and L. Trujillo. 2002. "What Does Privatization do for Efficiency? Evidence from Argentina's and Brazil's Railways." World Development 30(11): 1885-1897.

Farsi, M. and M. Filippini. 2004. "Regulation and Measuring Cost Efficiency with Panel Data Models Application to Electricity Distribution Utilities." Review of Industrial Organization 25(1): 1-19.

Farsi, M., M. Filippini and M. Kuenzle. 2005. "Unobserved Heterogeneity in Stochastic Cost Frontier Models: An Application to Swiss Nursing Homes." Forthcoming in Applied Economics.

Farsi, M., M. Filippini and M. Kuenzle. 2006. "Cost efficiency in regional bus companies: An application of new stochastic Frontier Models." Forthcoming in Journal of Transport Economics and Policy.

Federal Office of Transport. 2003. Railway Reform 2, Swiss Federal Office of Transport Report, available in French (Réform des chemins de fer 2) and German (Bahnreform 2) at http://www.bav.admin.ch/.

Filippini, M. 1996. "Economies of Scale and Utilization in the Swiss Electric Power Distribution Industry." Applied Economics 28: 543-550.

Filippini, M. and P. Prioni. 2003. "The Influence of Ownership on the Cost of Bus Service Provision in Switzerland: An Empirical Illustration." Applied Economics 35(6): 683-690.

Filippini, M. and R. Maggi. 1993. "Efficiency and Regulation in the Case of the Swiss Private Railways." Journal of regulatory Economics 5: 199-216.

Gathon, H. J. and S. Perelman. 1992. "Measuring Technical Efficiency in European Railways: A Panel Data Approach." Journal of Productivity Analysis 3: 135-151.

Greene, W. 2005. "Reconsidering Heterogeneity in Panel Data Estimators of the Stochastic Frontier Model." Journal of Econometrics, 126(2): 269-303.

Greene, W. 2004. "Distinguishing Between Heterogeneity and Inefficiency: Stochastic Frontier Analysis of the World Health Organization's Panel Data on National Health Care Systems." Health Economics 13: 959-980.

Greene, W. 2002. "Alternative Panel Data Estimators for Stochastic Frontier Models." Working paper, Stern School of Business, New York University (September 2002).

Greene, W. 1997. "Frontier Production Functions." In Handbook of Applied Econometrics, Vol. II. Microeconomics, edited by M. H. Pesaran and P. Schmidt, Chapter 3, pp. 81-166.

Guyomard, H. and D. Vermersch. 1989. "Derivation of Lung-run Factor Demands from Short-run Responses." Agricultural Economics 3: 213-230.

Heshmati, A. and S. C. Kumbhakar. 1994. "Farm Heterogeneity and Technical Efficiency: Some Results from Swedish Dairy Farms." Journal of Productivity Analysis 5(1): 45-61.

Hsiao, C. 2003. Analysis of Panel Data, 2nd edition, Cambridge University Press.

Ivaldi, M. and G. J. Mc Cullough. 2001. "Density and Integration Effects on Class I U.S. Freight Railroads." Journal of Regulatory Economics 19(2): 161-182.

Jondrow, J., I. Materov, K. Lovell and P. Schmidt. 1982. "On the Estimation of Technical Inefficiency in the Stochastic Frontier Production Function Model.” Journal of Econometrics 19: 233-238. 
Kumbhakar, S. C. 1991. "Estimation of Technical Inefficiency in Panel Data Models with Firm- and Time-specific Effects." Economics Letters 36: 43-48.

Kumbhakar, S. C. and L. Hjalmarsson. 1995. "Estimation of Technical Inefficiency in Panel Data Models with Firm- and Time-specific Effects." Journal of Applied Econometrics 10: 33-47.

Kumbhakar, S. C. and C. A. K. Lovell. 2000. Stochastic Frontier Analysis. Cambridge: Cambridge University Press, Cambridge.

Mancuso, P. and P. Reverberi. 2003. "Operating Costs and Market Organization in Railway Services, The Case of Italy, 1980-1995.” Transportation Research Part B 37: 43-61.

Mizutani, F. 2004. "Privately Owned Railways' Cost Function, Organization Size and Ownership", Journal of Regulatory Economics 25(3): 297-322.

Mundlak, Y. 1978. "On the Pooling of Time-series and Cross-section data." Econometrica 64(1): 69-85. Oum, T. H., W. G. Waters II and C. Yu. 1999. "A Survey of Productivity and Efficiency Measurement in Rail Transport." Journal of Transport Economics and Policy 33(1): 9-42.

Pitt, M. and L. Lee. 1981. "The Measurement and Sources of Technical Inefficiency in Indonesian Weaving Industry." Journal of Development Economics 9: 43-64.

Savage, I. 1997. "Scale Economies in the United States Rail Transit Systems." Transport Research 31A: 459-473.

Schleifer, A. 1985. "A Theory of Yardstick Competition." Rand Journal of Economics 16(3): 319-327.

Schmidt, P. and R. E. Sickles. 1984. "Production Frontiers and Panel Data." Journal of Business and Economic Statistics 2: 367-374.

Todani, K. R. 2001. Determinants of Price-Cost Margins in the U.S. Railroad Industry: An Econometric Investigation, $\mathrm{PhD}$ Dissertation, University of Minnesota.

Tromp, M. 2003. "Oeffentlicher Verkehr im Spannungsfeld von Wettbewerb und Service Public." Die Volkswirtschaft 12: 26-30. 